\title{
Enteral nutrition in the biologic era: learn from yesterday, live for today, hope for tomorrow
}

\author{
Tadakazu Hisamatsu \\ Department of Gastroenterology and Hepatology, Kyorin University School of Medicine, Mitaka, Japan
}

\section{Article: Exclusive enteral nutrition for induction of remission in anti-tumor necrosis factor refractory adult Crohn's disease: the Indian experienc (Intest Res 2020;18:184-191)}

In the current issue of Intestinal Research, Sood et al. ${ }^{1}$ reported the efficacy of exclusive enteral nutrition (EEN) for the induction of remission in adult patients with $\mathrm{CD}$ who were refractory to TNF inhibitors. Six patients who were refractory to TNF inhibitors received EEN for 12 weeks as a salvage therapy. Among them, 4 patients (66.6\%) achieved clinical remission. In addition, improvement of perianal and entero-enteric fistulas was observed in some patients. EEN also improved BMI (from $15.6 \pm 3.1$ to $18.9 \pm 1.9 \mathrm{~kg} / \mathrm{m}^{2}$ ), hemoglobin levels (from $8.2 \pm 1.1$ to $12.6 \pm 0.6 \mathrm{~g} / \mathrm{dL}$ ), and serum albumin levels (from $2.8 \pm 0.3$ to $3.6 \pm 0.5 \mathrm{~g} / \mathrm{dL}$ ). All 6 patients were L3 (ileocolonic). Two of the 6 were B2 (stricturing) and the other 4 were B3 (penetrating). With TNF inhibitors becoming the mainstay of treatment for $\mathrm{CD}$, managing primary nonresponders and patients that lose responsiveness to TNF inhibitors is an important issue. In this respect, the results of this study showing that EEN was effective in patients who were refractory to TNF inhibitors is significant.

There are several unsolved issues in this study. Most importantly, endoscopic assessment was not performed. EEN is presumed to be more effective for small bowel lesions than large bowel lesions. The difference in endoscopic improve-

Received December 30, 2019. Accepted January 3, 2020 Correspondence to Tadakazu Hisamatsu, Department of Gastroenterology and Hepatology, Kyorin University School of Medicine, 6-20-2 Shinkawa, Mitaka 181-8611, Japan. Tel: +81-422-47-5511 (ext. 5729), Fax: +81-42244-0655, E-mail: thisamatsu@ks.kyorin-u.ac.jp ment between small and large bowel lesions in ileocolonic type patients is of interest. This study sets clinical remission and fistula healing at week 12 as the primary endpoints. The subsequent clinical course of patients in whom EEN has shown efficacy should be followed. When considering the long-term management of $\mathrm{CD}$, a few questions remain including: What is the appropriate maintenance therapy in patients who are in remission with EEN? Is continuous EEN over 12 weeks necessary? Is it necessary to switch to appropriate medication?

The efficacy of enteral nutrition (EN) for CD was first reported in 1974 by Bounous et al. ${ }^{2}$ They reported 9 cases of "regional enteritis" who were treated with EN. Since then, its efficacy has mainly been reported in pediatric CD patients, and is still recommended. ${ }^{3}$ On the other hand, evidence of EN for adult $\mathrm{CD}$ is not sufficient. The superiority of EN in comparison to pharmacotherapy in the induction of remission has not been proven, and there is some evidence for remission maintenance therapy. ${ }^{4,5}$

A major problem with EN in adult patients with $\mathrm{CD}$ is poor adherence, because EN forces patients to restrict their diet. As large-scale, double-blind, placebo-controlled trials regarding EN are not realistic, high-quality evidence will continue to be difficult to generate. However, there are cases in adult CD patients who require EN in actual clinical practice such as patients with small intestinal or stenotic lesions. It is also true that EN is being re-evaluated in the biologics era as an adjuvant treatment. ${ }^{6}$ Takagi et al. ${ }^{7}$ reported that a half elementary 
diet was effective in preventing relapse in postoperative CD patients. Hirai et al. ${ }^{8}$ reported the effectiveness of a combination therapy of EN with TNF inhibitors. In addition, concomitant use of EN with dose escalation of TNF inhibitors in patients with a loss of response has been investigated. ${ }^{9}$ Thus, even in the biologics era, this editor believes that $\mathrm{EN}$ remains a viable treatment for CD especially since biologics are not as readily available in all countries. Its use is influenced by the approval status, insurance systems, and medical economics in each country. Also, in areas where the risk of infectious disease is high, concerns regarding biologics use are also relatively high, and EN remains a safe treatment option. In high endemic areas of intestinal tuberculosis and infectious enterocolitis, the use of biologics for the initial treatment may be hesitant.

Although the mechanism of action of EN in humans has not been fully elucidated, animal models have demonstrated that EN can influence epithelial barrier function, host metabolic status, and gut flora composition. There are reports of EN with various compositions, but the composition of $\mathrm{EN}$ that is most suitable for treating CD has not been determined. Considering the disease state, pharmacotherapy, including biologics, mainly have an inhibitory effect on inflammation and is not a fundamental treatment. With the role of the gut flora in IBD being particularly noted, the impact of EN on gut flora and metabolism may be worth reconsidering. From there, the best composition of EN and new therapeutic targets for CD can be discovered.

By re-reviewing EN, a historical treatment, this editor believes we can get clues for establishing new preventive medicine for IBD. "Learn from yesterday, live for today, hope for tomorrow"Albert Einstein.

\section{FINANCIAL SUPPORT}

The author received no financial support for the research, authorship, and/or publication of this article.

\section{CONFLICT OF INTEREST}

No potential conflicts of interest relevant to this article were reported.

\section{AUTHOR CONTRIBUTION}

Writing and approval of final manuscript: Hisamatsu T.

\section{ORCID}

Hisamatsu T https://orcid.org/0000-0002-1178-3536

\section{REFERENCES}

1. Sood A, Singh A, Sudhakar R, et al. Exclusive enteral nutrition for induction of remission in anti-tumor necrosis factor refractory adult Crohn's disease: the Indian experience. Intest Res 2020;18:184-191.

2. Bounous G, Devroede G, Haddad H, Beaudry R, Perey BJ, Lejeune LP. Use of an elemental diet for intestinal disorders and for the critically ill. Dis Colon Rectum 1974;17:157-165.

3. Forbes A, Escher J, Hébuterne X, et al. ESPEN guideline: clinical nutrition in inflammatory bowel disease. Clin Nutr 2017; 36:321-347.

4. Narula N, Dhillon A, Zhang D, Sherlock ME, Tondeur M, Zachos M. Enteral nutritional therapy for induction of remission in Crohn's disease. Cochrane Database Syst Rev 2018;4:CD000542.

5. Akobeng AK, Zhang D, Gordon M, MacDonald JK. Enteral nutrition for maintenance of remission in Crohn's disease. Cochrane Database Syst Rev 2018;8:CD005984.

6. Nguyen DL, Palmer LB, Nguyen ET, McClave SA, Martindale RG, Bechtold ML. Specialized enteral nutrition therapy in Crohn's disease patients on maintenance infliximab therapy: a metaanalysis. Therap Adv Gastroenterol 2015;8:168-175.

7. Takagi S, Utsunomiya K, Kuriyama S, et al. Effectiveness of an 'half elemental diet' as maintenance therapy for Crohn's disease: a randomized-controlled trial. Aliment Pharmacol Ther 2006;24:1333-1340.

8. Hirai F, Ishihara H, Yada S, et al. Effectiveness of concomitant enteral nutrition therapy and infliximab for maintenance treatment of Crohn's disease in adults. Dig Dis Sci 2013;58:13291334.

9. Hisamatsu T, Kunisaki R, Nakamura S, et al. Effect of elemental diet combined with infliximab dose escalation in patients with Crohn's disease with loss of response to infliximab: CERISIER trial. Intest Res 2018;16:494-498. 